\title{
DYNAMICS OF PERSONALITY CHANGES IN PRISONERS AS A RESULT OF THE SOCIAL WORK WITH THEM
}

\author{
K. Benkova, A. Stoykov*, V. Shosheva, R. Vasilev, Y. Georgiev \\ Department of Social Activities, Faculty of Medicine, Trakia University, Stara Zagora, Bulgaria
}

\begin{abstract}
This article deals with the dynamics of personality changes in people serving a prison sentence whereas these changes are as result of the social work performed in prisons. Analyzed are some personality characteristics displayed in the context of emotional intelligence and social empathy in people with delinquent behavior of different age and of different social, educational, psychosomatic and family status.
\end{abstract}

Key words: Social Empathy, Anxiety, Emotional Intelligence

\section{INTRODUCTION}

Prisons accommodate people of different social, educational and psychological status.

Observations on these people in their immediate environment reveal certain dynamics in their overall mental state, but also a certain level of conservatism with respect to some expected changes.

Social work with people deprived of their liberty covers various activities involving training, labour, specialized work in a group, culture and information activity, sports activity and religious support. Social workers perform a huge number of diverse activities in the mentioned areas of interaction with the people deprived of their liberty held at the prisons in Stara Zagora and Pazardzhik.

A research to study some typical personality characteristics which are directly related to the expected changes which might occur as a result of the process of interaction has been carried out with the prisoners. Lecturers at the Department of Social Work with the Faculty of Medicine at Trakia University have also been involved.

We have taken into consideration the fact that upon their placement in prison, prisoner's personality is in a crisis situation, as well as the

\footnotetext{
*Correspondence to: Anton Stoykov, Trakia University, Faculty of Medicine, Department of Social Activities, 11 "Armeiska" street, 6000, Stara Zagora, Bulgaria, telephone: 0884737741, e-mail: stoykov70@abv.bg
}

fact that at the time of the crisis intervention each individual demonstrates different and strictly individual reactions as a result of their personality structure.

The expected changes as a result of the individual's stay in prison and the undertaken individual and group interventions usually are associated with positive changes. The dynamics which has been observed in prisoners accommodated in the prisons in Stara Zagora and Pazardzhik, is a result of the active social work with particular accents on:

- Coping with life problems by change in the thinking pattern;

- Overcoming and/or mitigation of the assertive behavior connected with different types of addictions;

- Raising tolerance in different communities;

- Preparation for adjusting to life after prison;

- Religious support to those deprived of their liberty;

- Health studies

- Activation of each prisoner's inner resources by cultural and sports activity and education;

It is completely logical to admit that implementation of the activities in their essentials with regard to each of the above accents, undergoes changes in a very specific way depending on the particular group of prisoners.

\section{RESULTS AND DISCUSSION}

The interest towards such a research is provoked, as we have already pointed out, by the fact that the group of prisoners is not homogeneous. The huge variety of 
BENKOVA K., et al.

individualities is decisive in terms of reshaping the result of each activity.

The research study is connected with the measurement of several indicators determining particular personality traits: social empathy, emotional intelligence and anxiety. The research was conducted in May-August, 2015 and October-December, 2016.

Table 1. Level of Social Empathy (ascertaining stage)

\begin{tabular}{|c|c|c|c|c|c|}
\hline \multicolumn{5}{|c|}{ Distribution of respondents by age } & \multirow{2}{*}{} \\
\cline { 1 - 5 } $20-30$ & $30-40$ & $40-50$ & $50-60$ & $60-70$ & Average \\
\hline 19,43 & 20,7 & 20,14 & 20 & 23 & $\mathbf{2 0 , 6 5}$ \\
\hline
\end{tabular}

Comments:

In the ascertaining stage (Table 1), the highest score in terms of social empathy show the prisoners in the age range of 40 to50, followed by the prisoners in the age range of 30 to 40 .
The participants in the research study are in the age range of 20 to 75 . They have different sentence length, and are of different psychological, social and educational status. The results of the ascertaining study conducted at the beginning revealed the following:
The lowest score is that of the prisoners in the age range of 20 to 30 .

With regard to anxiety, the highest score is that of the prisoners in the age range of 60 to 70 $(13,71)$, and it is the lowest in the prisoners aged $30-40(8,44)$.

Table 2. Emotional Intelligence Test (ascertaining stage)

\begin{tabular}{|c|c|c|c|c|c|}
\hline \multicolumn{5}{|c|}{ Distribution of respondents by age } & \\
\cline { 1 - 5 } $20-30$ & $30-40$ & $40-50$ & $50-60$ & $60-70$ & Average \\
\hline 11,71 & 8,44 & 8,57 & 9,67 & 13,5 & $\mathbf{1 0 , 3 8}$ \\
\hline
\end{tabular}

The results from the Emotional Intelligence Test (Table 2) show the following tendencies with regard to each item:

Table 2.1. Emotional Awareness (ascertaining stage)

\begin{tabular}{|c|c|c|c|c|c|}
\hline \multicolumn{5}{|c|}{ Distribution of respondents by age } & \multirow[b]{2}{*}{ Average } \\
\hline $20-30$ & $30-40$ & $40-50$ & $50-60$ & $60-70$ & \\
\hline 4,57 & 4,1 & 4,85 & 4,33 & 4,5 & 4,47 \\
\hline
\end{tabular}

The highest score with regard to the awareness about the emotions of others (Table 2.1) is seen in the age range of 40 to $50(4,85)$, followed by the $20-30$ age group $(4,57)$ and the lowest score is seen in the individuals in the age range of 30 to $40(4,1)$.
With regard to Table 2.2 "Controlling Your Own Emotions", there is a full match of the results with Item 1 for the age group 40-50, where the indexes are the same $(4,85)$. However, the score is higher for the individuals in the age range of 50 to $60(4,66)$, and it is the lowest in the 30-40 age group (3, 5).

Table 2.2. "Controlling Your Own Emotions" (ascertaining stage)

\begin{tabular}{|c|c|c|c|c|c|}
\hline \multicolumn{7}{|c|}{ Distribution of respondents by age } & \multirow{2}{*}{} \\
\cline { 1 - 5 } $20-30$ & $30-40$ & $40-50$ & $50-60$ & $60-70$ & Average \\
\hline 4,14 & 3,5 & 4,85 & 4,66 & 4 & $\mathbf{4 , 2 3}$ \\
\hline
\end{tabular}

The results under Table 2.3 "Self-Motivation" again show that the highest score for the 40-50 age group, i.e. $(5,57)$, followed by the people aged 60-70 (5) and the lowest score is that of the people in the age range of 50 to 60 years $(4,66)$. 
Table 2.3. "Self-Motivation" (ascertaining stage)

\begin{tabular}{|c|c|c|c|c|c|}
\hline \multicolumn{5}{|c|}{ Distribution of respondents by age } & \multirow{2}{*}{ Average } \\
\cline { 1 - 5 } $20-30$ & $30-40$ & $40-50$ & $50-60$ & $60-70$ & 4,98 \\
\hline 4,85 & 4,8 & 5,57 & 4,66 & 5 & $\mathbf{4 , 9 8}$ \\
\hline
\end{tabular}

Table 2.4. "Empathy" (ascertaining stage)

\begin{tabular}{|c|r|r|r|r|r|}
\hline \multicolumn{2}{|c|}{ Distribution of respondents by age } & \multirow{2}{*}{ Average } \\
\hline $20-30$ & \multicolumn{1}{|l|}{$30-40$} & $40-50$ & $50-60$ & $60-70$ & Averann \\
\hline 4,71 & 4,5 & 5,14 & 5,14 & 6 & $\mathbf{5 , 1 0}$ \\
\hline
\end{tabular}

With regard to the ascertaining stage ref. Table $\mathbf{2 . 4}$, it can be seen that the highest score in terms of empathy is in the 60-70 age group (6), and it is the lowest in the people aged 3040 .
The results with regard to the Table $\mathbf{2 . 5}$ "Recognizing Emotions of Others" are similar, almost identical for the 40-50 and 50-60 age groups $(5,28)$. The score is the lowest for the people in the age range of 20 to $30(3,71)$.

Table 2.5 "Recognizing Emotions of Others" (ascertaining stage)

\begin{tabular}{|c|c|c|c|c|c|}
\hline \multicolumn{5}{|c|}{ Distribution of respondents by age } & \multirow{2}{*}{ Average } \\
\hline $20-30$ & $30-40$ & $40-50$ & $50-60$ & $60-70$ & Avern \\
\hline 3,71 & 4,2 & 5,28 & 5,28 & 5 & 4,69 \\
\hline
\end{tabular}

The overall result in the ascertaining stage of this test reveals that the highest score is that of the age groups $40-50$ and $50-60(25,71)$ and the lowest score is that of the age group of 3040.

Table 3. Level of Emotional Intelligence (ascertaining stage)

\begin{tabular}{|c|c|c|c|c|c|}
\hline \multicolumn{5}{|c|}{ Distribution of respondents by age } & \multirow{2}{*}{ Average } \\
\hline $20-30$ & $30-40$ & $40-50$ & $50-60$ & $60-70$ & 23,92 \\
\hline 23 & 20,7 & 25,71 & 25,71 & 24,5 & $\mathbf{2 3 , 9}$ \\
\hline
\end{tabular}

After a period of social work performed with the people deprived of liberty, a check measurement took place and the comparative analysis of the results revealed the following:

\begin{tabular}{|c|c|c|c|c|c|}
\hline \multicolumn{5}{|c|}{ Distribution of respondents by age } & \multirow{2}{*}{ Average } \\
\hline $20-30$ & $30-40$ & $40-50$ & $50-60$ & $60-70$ & 20,65 \\
\hline 19,43 & 20,7 & 20,14 & 20 & 23 & $\mathbf{2 0 , 6}$ \\
\hline
\end{tabular}

Table 4. (controlling stage)

\begin{tabular}{|c|c|c|c|c|c|}
\hline \multicolumn{5}{|c|}{ Distribution of respondents by age } & \multirow[b]{2}{*}{ Average } \\
\hline $20-30$ & $30-40$ & $40-50$ & $50-60$ & $60-70$ & \\
\hline 20,71 & 17,7 & 19,16 & 22,66 & 16,5 & 19,35 \\
\hline
\end{tabular}

The score values are higher in the group of people aged 20-30 and 50-60. At the same

time, they are lower in the 30-40, 40-50 and 60-70 age groups.

Table 5. "Anxiety” Test (Table 2)

\begin{tabular}{|c|c|c|c|c|c|}
\hline \multicolumn{5}{|c|}{ Distribution of respondents by age } & \multirow{2}{*}{ Average } \\
\hline $20-30$ & $30-40$ & $40-50$ & $50-60$ & $60-70$ & 10,38 \\
\hline 11,71 & 8,44 & 8,57 & 9,67 & 13,5 & $\mathbf{1 0 , 3 8}$ \\
\hline
\end{tabular}


Table 5.1. "Anxiety" Test (Controlling Stage)

\begin{tabular}{|c|c|c|c|c|c|}
\hline \multicolumn{5}{|c|}{ Distribution of respondents by age } & \multirow{2}{*}{ Average } \\
\hline $20-30$ & $30-40$ & $40-50$ & $50-60$ & $60-70$ & A \\
\hline 9,14 & 9,71 & 6,71 & 11,33 & 16,5 & $\mathbf{1 0 , 6 8}$ \\
\hline
\end{tabular}

Higher levels of anxiety are seen in the individuals in the age range of 30 to 40,50 to 60 and 60 to 70 . Anxiety levels are lower in the 20-30 and 40-50 age groups. These results may be linked with the duration of the prison stay, difficult adaptation to the environment, and in other cases with the provision of living conditions, protection, the possibility to share without fear, as this refers probably to the people in the age range of 20 to 30 , who reduce their anxiety levels and who have better adaptation skills.

Interesting is the analysis of the results from the "Emotional Intelligence" Test with respect to each of the monitored indicators.

(Table 2.1) Emotional AwarenessAscertaining and Controlling Stage

Emotional Awareness-Ascertaining Stage

\begin{tabular}{|c|c|c|c|c|c|}
\hline \multicolumn{5}{|c|}{ Distribution of respondents by age } & \multirow{2}{*}{} \\
\cline { 1 - 5 } $20-30$ & $30-40$ & $40-50$ & $50-60$ & $60-70$ & Average \\
\hline 4,57 & 4,1 & 4,85 & 4,33 & 4,5 & $\mathbf{4 , 4 7}$ \\
\hline
\end{tabular}

Table 5.2. Emotional Awareness-Controlling Stage

\begin{tabular}{|c|c|c|c|c|c|}
\hline \multicolumn{5}{|c|}{ Distribution of respondents by age } & \multirow{2}{*}{} \\
\cline { 1 - 5 } $20-30$ & $30-40$ & $40-50$ & $50-60$ & $60-70$ & Average \\
\hline 4,28 & 3,5 & 4,42 & 5 & 4 & $\mathbf{4 , 2 4}$ \\
\hline
\end{tabular}

Therefore, with reference to the Item "Emotional Awareness" (Table 2.1), increased values (4,33 to 5) are seen only for the age range 50-60. For all other age groups, these values show a decrease. It can be assumed that this age is associated also with individual's social maturity, with the individual's interest in the other person, with the individual's concern for the younger.

Table 6. "Control of Emotions" - Ascertaining and Controlling Stage

Controlling Your Own Emotions-Ascertaining Stage

\begin{tabular}{|c|c|c|c|c|c|}
\hline \multicolumn{5}{|c|}{ Distribution of respondents by age } & \multirow{2}{*}{ Average } \\
\hline $20-30$ & $30-40$ & $40-50$ & $50-60$ & $60-70$ & Annnnnn \\
\hline 4,14 & 3,5 & 4,85 & 4,66 & 4 & $\mathbf{4 , 2 3}$ \\
\hline
\end{tabular}

Controlling Your Own Emotions-Controlling Stage

\begin{tabular}{|c|c|c|c|c|c|}
\hline \multicolumn{5}{|c|}{ Distribution of respondents by age } & \multirow{2}{*}{ Average } \\
\hline $20-30$ & $30-40$ & $40-50$ & $50-60$ & $60-70$ & Avenn \\
\hline 4,57 & 4,1 & 4,85 & 4,66 & 4,5 & $\mathbf{4 , 5 4}$ \\
\hline
\end{tabular}

The comparative analysis (Table 6) unquestionably indicates an increase in the values for all age groups, which gives us grounds to admit that the social work in this aspect has achieved good results.

Table 7 "Self-Motivation"-Ascertaining and Controlling Stage

Self-Motivation-Ascertaining Stage

\begin{tabular}{|c|c|c|c|c|c|}
\hline \multicolumn{5}{|c|}{ Distribution of respondents by age } & \multirow{2}{*}{ Average } \\
\hline $20-30$ & $30-40$ & $40-50$ & $50-60$ & $60-70$ & An \\
\hline 4,85 & 4,8 & 5,57 & 4,66 & 5 & $\mathbf{4 , 9 8}$ \\
\hline
\end{tabular}


Self-Motivation-Controlling Stage

BENKOVA K., et al.

\begin{tabular}{|c|c|c|c|c|c|}
\hline \multicolumn{5}{|c|}{ Distribution of respondents by age } & \multirow{2}{*}{ Average } \\
\hline $20-30$ & $30-40$ & $40-50$ & $50-60$ & $60-70$ & 4,80 \\
\hline 5 & 4 & 4,85 & 5,66 & 4,5 & $\mathbf{4}$ \\
\hline
\end{tabular}

With regard to the item "Self-Motivation" again there is an interesting dynamics (Table 7), i.e. there is an increase in the values with almost 1 unit in the group of people aged 50-
60 (from 4,66 to 5,66) and a slight increase in the group of those aged 20-30 (from 4,85 to 5). In terms of displaying of empathy, however, there is a tendency for a decrease in all age groups.

Table 8. "Empathy" - Ascertaining and Controlling Stage

Empathy - Ascertaining Stage

\begin{tabular}{|c|c|c|c|c|c|}
\hline \multicolumn{5}{|c|}{ Distribution of respondents by age } & \multirow{2}{*}{ Average } \\
\hline $20-30$ & $30-40$ & $40-50$ & $50-60$ & $60-70$ & \\
\hline 4,71 & 4,5 & 5,14 & 5,14 & 6 & $\mathbf{5 , 1 0}$ \\
\hline
\end{tabular}

Empathy-Controlling Stage

\begin{tabular}{|c|c|c|c|c|c|}
\hline \multicolumn{5}{|c|}{ Distribution of respondents by age } & \multirow{2}{*}{ Average } \\
\hline $20-30$ & $30-40$ & $40-50$ & $50-60$ & $60-70$ & 4,31 \\
\hline 3,85 & 4,2 & 5 & 4 & 4,5 & $\mathbf{4 , 3 1}$ \\
\hline
\end{tabular}

A similar decrease is seen also in the other indicator "Recognizing Emotions of Others"

Table 9. "Recognizing Emotions of Others" - Ascertaining and Controlling Stage

\begin{tabular}{|c|c|c|c|c|c|}
\hline \multicolumn{5}{|c|}{ Distribution of respondents by age } & \multirow{2}{*}{ Average } \\
\hline $20-30$ & $30-40$ & $40-50$ & $50-60$ & $60-70$ & $\mathbf{4 , 6 9}$ \\
\hline 3,71 & 4,2 & 5,28 & 5,28 & 5 & . \\
\hline
\end{tabular}

Recognizing Emotions of Others-Controlling Stage

\begin{tabular}{|c|c|c|c|c|c|}
\hline \multicolumn{5}{|c|}{ Distribution of respondents by age } & \multirow{2}{*}{ Average } \\
\hline $20-30$ & $30-40$ & $40-50$ & $50-60$ & $60-70$ & A, 1 \\
\hline 4,28 & 4,4 & 4,71 & 4,66 & 3,5 & $\mathbf{4 , 3 1}$ \\
\hline
\end{tabular}

The connection between those two items and the relevant results is logical, since a person is able to show empathy only when that person is able to recognize the emotions of others (Table 9). Still, there is the question why in this case there is a tendency for a decrease in the values. What are the reasons for this, what is hidden in each age with respect to each individual so that achievement of these changes is possible; furthermore, these changes are registered at time intervals when this individual is still in prison.

The general level reflected in the values of the item "Level of Emotional Intelligence" (Table 10) shows a decrease in all age groups.

Table 10. "Level of Emotional Intelligence"- Ascertaining and Controlling Stage

Level of Emotional Intelligence - Ascertaining Stage

\begin{tabular}{|c|c|c|c|c|c|}
\hline \multicolumn{5}{|c|}{ Distribution of respondents by age } & \multirow{2}{*}{ Average } \\
\hline $20-30$ & $30-40$ & $40-50$ & $50-60$ & $60-70$ & 23,92 \\
\hline 23 & 20,7 & 25,71 & 25,71 & 24,5 & $\mathbf{2 3 , 9}$ \\
\hline
\end{tabular}

Level of Emotional Intelligence - Controlling Stage

\begin{tabular}{|c|c|c|c|c|c|}
\hline \multicolumn{5}{|c|}{ Distribution of respondents by age } & \multirow{2}{*}{ Average } \\
\hline $20-30$ & $30-40$ & $40-50$ & $50-60$ & $60-70$ & 21 \\
\hline 21,42 & 20,1 & 23,85 & 24 & 21 & $\mathbf{2 2 , 0 7}$ \\
\hline
\end{tabular}




\section{CONCLUSION}

The general conclusion which can be drawn at present as a result of the conducted research study is that in prisons work with regard to the control of prisoners' emotions is being performed fairly in the right direction. The social work with prisoners should have a wider scope meaning that it should be able to activate processes connected with a change in the individual's personality traits at different stages of the individual's development.
The process of social work with groups or individuals requires that with regard to each particular intervention, the methods, approaches and means used, are able to provide possibilities for measurement of the results achieved at that given time, and also for undertaking the relevant corrective actions.

The research study carried out covers a period of 8 months which are enough to ascertain positive or negative changes, or stasis in the results of the social work performed. 